CLINICAL HEMORHEOLOGY, Vol. 1, pp. 111-116, 1981

$0271-5198 / 81 / 020111-06 \$ 02.00 / 0$ Printed in the USA.

Copyright (c) 1981 Pergamon Press Ltd. All rights reserved.

\title{
EDITORIAL
}

NEW EDITORS, NEW INFORMATION, EMPHASIS ON INSTRUCTIONS TO AUTHORS, AND THE FIELD OF CLINICAL HEMORHEOLOGY

\section{NEW EDITORS}

According to the Foreword in issue number 1 , it was stated that a total of twenty-four Editors will be appointed and that the Editorial Board will not be completed during the first year. We and the Publishers are, therefore, pleased to welcome M.R. Boisseau (Bordeaux, France) and G.A. Marcel (Paris, France) as Editors.

\section{NEW INFORMATION}

Some points, made in the Foreword of August 15, 1980 in the first issue of CLINICAL HEMORHEOLOGY, need to be clarified and expanded. They are dealt with in more detail and other information is given under separate headings.

\section{Publication Schedule}

Last spring one of us (ALC) was advised by the Publishers about the dates of publication of CLINICAL HEMORHEOLOGY. They were included in the Foreword as follows: "The first two issues of CLINICAL HEMORHEOLOGY, published in 1980, and the remaining four issues, published in 1981, will comprise volume 1. Each subsequent volume, beginning with volume 2 in 1982, will contain 6 issues per year."

The first issue of CLINICAL HEMORHEOLOGY has appeared in 1980 close to the anticipated schedule. It is emphasized that it would have been most difficult to compile the contributions for the second issue for advance publication in 1980, because most Authors did not adhere strictly to the Instructions. The publication schedule of CLINICAL HEMORHEOLOGY has, therefore, been changed. The Journal will now be published on a regular basis every two months. 


\section{Republication of Abstracts}

Details about the republication of abstracts are given in the Foreword of the previous issue.

An abstract form with directions is available to our Readers and can be obtained from either K.-U. Benner, Editor of Abstract Section, (whose address is given in each issue of CLINICAL HEMORHEoLOGY,) or from any Editor.

Readers of CLINICAL HEMORHEOLOGY who know of Papers recently published in other journals (or in press) are asked to communicate with K.-U. Benner.

\section{Two New Types of Communications: 'Essay' and 'Commentary'}

Our Instructions to Authors, I. Submission of Communications, list (under A) four types of manuscripts, dealing with clinical hemorheology, viz., (A-1) Papers, (A-2) Brief Communications, (A-3) Letters to the Editors-in-Chief, and (A-4) Mini-Reports.

We now provide our Readers with two new types of communications, named 'Essay' (A-5) and 'Commentary' (A-6), to be submitted to an Editor-in-Chief.

Essays are meant to reflect opinions of an Author and concern articles which do not necessarily correspond entirely to the Aims of CLINICAL HEMORHEOLOGY, printed under Aims and Editorial Policy in each issue. An Essay has to be considered of interest to our Readers by the Editor-in-Chief, to whom it is submitted.

Essays, as well as other communications, are expected to invite comments from our Readers in the form of Letters to the Editors-in-Chief $(\mathrm{A}-3)$. In case such comments extend the limit of 2 pages for 'Letters to the Editors-in-Chief', they can be submitted as 'Commentary' (A-6) to the Editors-in-Chief. In other words, Commentaries are extended Letters to the Editors-in-Chief. The page limit of any Commentary and its acceptance for publication will be decided by the Editors-in-Chief.

\section{EMPHASIS ON INSTRUCTIONS TO AUTHORS}

We have asked our Editors to see to it that Authors who intend to submit communications to CLINICAL HEMORHEOLOGY adhere to our Instructions to Authors, published in each issue of our journal. This 
is necessary for rapid publication of any communication. The following points are, therefore, reemphasized.

A communication which is not presented in accordance with our Instructions to Authors should be returned by the Editor to whom it is submitted without a date of receipt. A communication can only be considered for publication by an Editor, if it adheres strictly to the Instructions to Authors.

Many Authors do not utilize the typing area in close proximity to the right vertical blue line of the laysheets. Words close to this line should be hyphenated, if necessary. It is advisable to use a standard English dictionary, such as the Oxford or Merriam-Webster versions, when deciding where to hyphenate words.

The communication must be typed single-spaced, clearly and neatly without any smudges. Each line should begin very close to the left vertical margin. There should be a double space between two paragraphs. It is preferable to have each paragraph begin with an indentation, although it has not been spelled out in the Instructions to Authors. Each indentation should always be the same for each paragraph and the indentation should have not more than five typewriter spaces.

It should be kept in mind that there is a $20 \%$ reduction of each figure to the final journal page size. It is, therefore, necessary to keep in mind that any lettering of the figure would still have to be clearly readable after its reduction. Figures cannot be enlarged, but larger figures can always be reduced. No figures or tables should be included under Discussion.

References need a double space between two subsequent references. The Authors' surnames need to be capitalized and both the first and last page number of each reference must be cited.

Key Words will have to be placed as a footnote on the bottom of the Title Page. Any other footnotes on the Title Page should be above the Key Words and be separated by one single line. We recommend to place a Running Title of not more than 32 typewriter spaces in blue pencil on the top of the Title Page or on a separate sheet. This includes the spacing between each word.

We have included in the Instructions to Authors so-called Mini- 
Reports as a type of manuscript to be considered for publication (see Instructions to Authors). Mini-Reports address practical problems in the laboratory and in clinical investigation.

There have been delays in the publication of manuscripts because of poor technical presentation which have been overlooked by the Editors. This made it necessary for the Executive Editorial Office (EEO) under the direction of one of us (ALC) to return the manuscript accepted by an Editor.

Editors and Authors are advised to inquire at the EEO about the publication of a manuscript accepted by an Editor, if it did not appear in print two months after its acceptance by the Editor. It goes without saying that the Editor is required not to delay in sending an accepted communication to the EEO with the required information of the date of receipt and, if revised, the date of receipt in revised form.

In case the revision of a manuscript is required, the Authors are advised to submit the revised manuscript to the Editor without delay.

It should be noted that, in case a communication has several Authors, the Editor and the EEO will communicate with the first Author, unless it is indicated in a footnote on the Title Page of the communication to whom correspondence should be addressed.

A Reprint Order Form has to be submitted regardless of whether or not the Author wishes to order reprints. The Copyright Form also has to be completed. Each Editor is required, upon acceptance of a manuscript for publication, to send these two forms to the Author. The two completed forms are to be sent without delay to the EEO. In case the Author does not reside in USA, Canada or Mexico, these forms will have to be sent by Air Mail.

The above recommendations to our Editors and to Authors of communications submitted for publication are meant to insure as rapid publication as possible.

\section{ON COMMUNICATIONS PERTAINING TO THE FIELD OF CLINICAL HEMORHEOLOGY}

This journal, as is indicated in its title, is restricted to the publication of original communications (Papers, Brief Communi- 
cations) in the field of clinical hemorheology. These contributions are not limited solely to clinical investigations. As can be noted from one of the Papers in the previous issue, CLINICAL HEMORHEOLOGY will include articles in which clinical materials or specimens are utilized in experimental animal studies. The emphasis will be on direct benefits to the practice of medicine in areas including pathogenesis, symptomatology, diagnostic methods, prophylactic and therapeutic measures, as stated under Aims and Editorial Policy. However, CLINICAL HEMORHEOLOGY will not include original communications (Papers and Brief Communications) pertaining to the mechanisms of certain disease processes which do not deal with materials or specimens from patients. Such original communications (Papers, Brief Communications) in the fields of experimental and theoretical hemorheology will continue to be published in BIORHEOLOGY to which CLINICAL HEMORHEOLOGY is, as indicated in its subtit1e, A COMPANION JOURNAL.

It should be noted that BIORHEOLOGY and CLINICAL HEMORHEOLOGY are now published in the same format and size, for which the same laysheets can be utilized. In case a Paper or Brief Communication has been prepared erroneously by an Author for publication in one of the two journals, viz., CLINICAL HEMORHEOLOGY or BIORHEOLOGY, the same manuscript could then be submitted, without retyping, vice versa to an Editor of the other journal, for which it was not intended initially by the Author.

We, therefore, should like to acquaint our Readers with what has been stated in a recent Editorial in BIORHEOLOGY (Vo1.17, No. 5/6, pp. 397-398, 1980):

"Communications on theoretical and experimental hemorheology will be published as before in BIORHEOLOGY. This is also the case with communications on clinical biorheology other than clinical hemorheology. However, communications on clinical hemorheology will need to be submitted from now on to an Editor of CLINICAL HEMORHEOLOGY.

Since CLINICAL HEMORHEOLOGY is a companion journal of BIORHEOLOGY, as stated in its subtitle, a communication on clinical hemorheology submitted to an Editor of BIORHEOLOGY can be sent by this Editor to an Editor of his/her choice to an Editor of CLINICAL HE- 
MORHEOLOGY. Conversely, a communication on theoretical hemorheology or experimental hemorheology can be sent by an Editor of CLINICAL HEMORHEOLOGY, to an Editor of his/her choice of BIORHEOLOGY. In both cases the Author will need to be informed to this effect by the Editor, to whom it was originally submitted, and by the Editor, who receives it. This procedure will make possible most rapid handling of a manuscript in the event it is not submitted to the proper journal."

It is hoped that the different types of articles dealing with clinical hemorheology, published in our Journal, will stimulate discussions and provide a forum in CLINICAL HEMORHEOLOGY which ultimately will be of benefit to the practice of medicine.

\author{
Alfred L. Copley Siegfried Witte \\ Editors-in-Chief
}

